\title{
Exploring the logic of mobile search ${ }^{\dagger}$
}

\author{
Oscar Westlund ${ }^{\mathrm{a}}$, José-Luis Gómez-Barroso ${ }^{\mathrm{b}}$, Ramón Compañó ${ }^{\mathrm{c}}$ and Claudio Feijóo ${ }^{\mathrm{d} *}$ \\ ${ }^{a}$ Department of Journalism, Media and Communication, University of Gothenburg, Gothenburg, Sweden; ${ }^{b}$ Dpto. Economía Aplicada \\ e Historia Económica, UNED - Universidad Nacional de Educación a Distancia, Madrid, Spain; ${ }^{c} I P T S$ - Institute for Prospective \\ Technological Studies, Directorate General Joint Research Centre - European Commission, Seville, Spain; ${ }^{d}$ CeDInt, Universidad \\ Politécnica de Madrid, Campus de Montegancedo, Pozuelo de Alarcón, Spain
}

\begin{abstract}
After more than a decade of development work and hopes, the usage of mobile Internet has finally taken off. Now, we are witnessing the first signs of evidence of what might become the explosion of mobile content and applications that will be shaping the (mobile) Internet of the future. Similar to the wired Internet, search will become very relevant for the usage of mobile Internet. Current research on mobile search has applied a limited set of methodologies and has also generated a narrow outcome of meaningful results. This article covers new ground, exploring the use and visions of mobile search with a users' interview-based qualitative study. Its main conclusion builds upon the hypothesis that mobile search is sensitive to a mobile logic different than today's one. First, (advanced) users ask for accessing with their mobile devices the entire Internet, rather than subsections of it. Second, success is based on new added-value applications that exploit unique mobile functionalities. The authors interpret that such mobile logic involves fundamentally the use of personalised and context-based services.
\end{abstract}

Keywords: mobile; phone; search; Internet; use; adoption

\section{Introduction}

For a long time, the telecom industry sought to develop killer applications for Internet accessed through the mobile. However, many such attempts have failed (Wilson 2006), and the use of mobile Internet remained modest during the first decade of the new millennium (Bohlin and Westlund 2008, Westlund 2008). Much development work and research was conducted, but no one seemed to identify the killer application for the mobile Internet. Then Apple ${ }^{\circledR}$ launched the iPhone ${ }^{(\mathbb{B}}$ and it became apparent that the solution was the usability - the interface - of the mobile device itself (Goggin 2009, West and Mace 2010) coupled with available and affordable mobile broadband (Feijóo and Gómez-Barroso 2009). What have followed are an extensive development of touchscreen devices and a rapid diffusion of mobile Internet usage. For example, in a country with high mobile penetration rates, such as Sweden, the use of mobile Internet had hardly increased during the years until 2008, but has more than doubled during 2009 (Westlund 2010a).

The further evolution will lead to an explosion of mobile content and applications (Feijóo et al. 2009a), a fundamental part of the expected mega-trends shaping the Internet of the future (Reding 2008). There are now growing business opportunities within the telecom industry, and there are also many stakeholders that are moving towards the mobile domain (Ramos et al. 2009). The emergence of the mobile as a multimedia device has stimulated the interest for mobile marketing (Feijóo et al. 2010), which becomes clear in a recent literature review of 53 cases presented in this journal (Park et al. 2008). A recent article concludes that there is much hope for mobile marketing, although this is an area still 'waiting for the kiss of life' (Wilken and Sinclair 2009).

Similarly to the wired Internet, many of upcoming mobile web models and applications will require access to data and content in an efficient and user-friendly manner. Search engines, which are already the main gateway for more than half of the users connecting to Internet through $\mathrm{PC}$, are also becoming important in mobile platforms (Cui and Roto 2008). Mobile search can intelligently be integrated with other mobile applications, such as is the case for iPhone, Android ${ }^{\mathbb{B}}$-based phones or any other of the various emerging platforms. Mobile search is, thus, becoming an increasingly important market area - and topic for research. For instance, according to Google sources (Gohring 2010) mobile search data traffic has grown by five times from 2008 to 2010 .

What will the future usage patterns of mobile look like? Certainly, the amount of research on the adoption

\footnotetext{
*Corresponding author. Email: cfeijoo@cedint.upm.es

The opinions expressed are purely those of the authors and may not in any circumstances be regarded as stating an official position of their institutions.
} 
and use of mobile Internet and services is growing. However, this evidence alone is not enough to capture the mobile search phenomenon. Bouwman et al. (2009) argue that in research on adoption and use of mobile services, one must investigate the unique characteristics and user values of each service or function. Moreover, mobile search has been largely overlooked in research and reports, as some examples indicate: ComScore M:Metrics (2008b) benchmark exercise included as many as 10 different mobile Internet activities, but none of their indicators took mobile search into account. Similarly, the prestigious Pew Internet reports on wireless Internet usage in the USA (Horrigan 2009) does not include mobile search among the 10 fundamental wireless services examined either. In addition, neither a report by Morgan Stanley from 2008 on iPhone usage studying 16 mobile service functions (Pascu 2008a) nor a survey carried out in Finland measuring the intentions and usage related to 17 mobile services (Verkasalo 2008) included mobile search as a distinct category.

Notwithstanding the apparent lack of systematic monitoring of the search phenomenon, mobile search is beginning to appear in the 'radar' of mobile market analysts basically for its relationship with advertisingbased business models, mostly with a 'local' flavour. For instance, a survey of research firm Compete (2010) covering 1246 smartphone users showed that pushed ads resulting from mobile search was an acceptable outcome for $16 \%$ of smartphone users. Mobile search is also slowly becoming a regular part of the studies about mobile usage. A survey in the Netherlands with 542 users (Bouwman et al. 2009) revealed that mobile search was one of the 16 types of services considered to demonstrate that lifestyles, i.e. "how people live, how they spend their money and how they allocate their time' have a decisive influence on the adoption of mobile solutions.

More particularly, a number of interesting studies specifically on mobile search use have emerged from 2008. One example is the focus group study with 11- to 16-year-old children in the United Kingdom, conducted by Haddon and Vincent (2008). The following quote is extracted from a discussion with a group of 11- to 12-year-old kids on what kind of mobile Internet services they wish to use (Haddon and Vincent 2008, p. 16).

Annabel: My friend, she forgot her homework. So she looked something up in Google on her phone and wrote the definition down.

Alicia: Wow. Oh, I want Google (...) I'd do my homework on the way to school.

This quote makes one consider if mobile search generally is as appealing for everybody as it is for
Alicia? From this we can ask ourselves a number of questions. How common it is among different nationalities and groups to use mobile search? In what ways do people use their mobile for search activities? What are the critical criteria for adopting mobile search? How is mobile search used in relation to mobile Internet?

Previous research has primarily addressed the first and second questions, while little research has been conducted to respond to the third and fourth questions. This means that little is known about needs and intentions for usage, and how usage of mobile search relates to users' other mobile Internet activities. There is a particular lack of qualitative explorations into the personal mindsets of users. This article empirically explores that particular area through a qualitative research approach: five focus groups with a variety of mobile users were conducted in Gothenburg, Sweden. Our ambition is to contribute to a better understanding of mobile search usage patterns, as well as explore new terrain through the study of adoption criteria.

The article starts with a review of the research and work which has been done in the area. In the following section we propose our study rationale; the purpose of the article, our theoretical framework and our methodological approach. Then follows an elaboration on our results and then comes a final section in which we present the conclusions.

\section{Research on mobile search usage}

For sake of simplicity, we will discuss usage of mobile search by mobile search usage in context and mobile search usage patterns. The mobile search usage in context contains available information on the extent and frequency of mobile search usage in ways that allow for cross-service comparisons. The mobile search usage patterns category on the other hand includes studies on mobile search usage based on analyses of large-scale logs from search engine databases. This approach has been most common in research on mobile search, revealing what people do, but not allowing to cross-check with users' demographics or users' experience (such as the context or 'inspiration' of the search activity).

\subsection{Mobile search usage in context}

Unfortunately, there is no reliable and updated data source for mobile search usage in context. Available data are gathered from surveys which, generally, have no extension in time. Acknowledging these limitations, the following can be found. 
In 2008, there were 20.8 million mobile search users in the United States $(9.2 \%)$ and 4.5 million in the five biggest European countries (5.6\%). This represents an increase of $68 \%$ and $38 \%$ from June 2007 , respectively. In addition to the rise in mobile search users, the report shows also that the frequency of activity is growing as high as close to $50 \%$ in all the countries. Analysts at ComScore explain this by an expanded $3 \mathrm{G}$ penetration, an increased adoption of advanced mobile devices, better offerings of mobile search services and flat-rate data plans (ComScore M:Metrics 2008a). More recent data from a BIA/Kelsey (2009) consumer study indicate that $19 \%$ of US subscribers searched the mobile web for local products and services in October 2009 , up from $16 \%$ in 2008 and $10 \%$ in 2007 .

By category, BIA/Kelsey (2009) notes that $16 \%$ of consumers obtained information about movies or other entertainment, $13 \%$ sought information about restaurants or bars and $11 \%$ searched for products or services outside their local area. The location relevancy is also stressed according to Google ${ }^{(\mathbb{B}}$ data from early 2010 (FierceWireless 2010), since one of every three mobile search queries received includes some element of local-specific intent. As another example along this same line of context - location - and search, Yahoo announced the introduction of a search application in March 2010 enabling users to draw a boundary on the mobile device map to discover local businesses within the established area.

Related to search engines, using data from Opera (2010), Google now accounts for more than $9 \%$ of all mobile web page views in the USA, compared with Yahoo's $4.3 \%$ of all page views and Microsoft's Bing at just $0.03 \%$. Indeed, Google remained the most visited US mobile website in terms of unique users with Facebook $^{\circledR}$ following in second place, trailed by Yahoo ${ }^{\mathbb{R}}$, Wikipedia ${ }^{\mathbb{R}}$ and MySpace ${ }^{\mathbb{R}}$. In all, searchportal related views made up $13.5 \%$ of total US mobile page views, with each unique user averaging 39.9 search-based page views per month.

Do smartphones make any difference? Very likely so, although there is hardly any publicly available data to support this evidence. Only Pascu (2008b) discusses two additional M:Metrics studies. The first study, carried out in the USA in January 2008 , shows that $58.6 \%$ of American iPhone owners used the mobile search function, compared with $37 \%$ among other smartphone users and just $4.6 \%$ for the entire mobile market. The second study in a European context (France, Germany and the United Kingdom) from July 2008 illustrates that mobile search is even more popular among iPhone users from these countries (more than $80 \%$ ). Meanwhile the number of other smartphones users who access the mobile search function ( $32 \%$ ) is less than in the USA and the total market is at an equivalent level.
Finally, there are also a few studies that have moved beyond the general patterns of usage to analyse usage among different groups of users. We have identified two survey-based studies, one from Sweden and one from Japan, both advanced nations in terms of ICT adoption. The Swedish survey (Bohlin et al. 2007) was carried out during 2007 and encompassed usage of the mobile for a number of functions. The study reported that while $13 \%$ of Swedes aged 16-65 used mobile Internet, only $6 \%$ used mobile search. The survey further illustrates a gender imbalance: men use mobile search more frequently than women. There was a gap between users aged 16-49 and those aged 50-65. Among the 16 49 year group, about one in five use Internet services on a monthly basis. The number is close to 1 in 10 for mobile search, witnessing about a similar gap in usage compared to people aged 50-65 years. There were significant differences in usage between different user groups, depending on which payment model they had picked up. While pre-paid card owners used mobile search the least, it was slightly more common among private-based subscribers, and especially among people with business subscription. The study shows also illustrated correlations of increased usage with high income, possession of a 3G-device and people with an expressed interest in new technology.

In turn, the Mobile Society Research Institute at NTT DoCoMo ${ }^{\circledR}$ has performed annual surveys from 2005 to 2007 (NTT DoCoMo 2007), which included questions on mobile search services to a similar age cohort of the Japanese population. The responses have been relatively stable over the years: about one in five Japanese said that they use or were going to use their mobile for search activities. Their results also illustrated search behaviour in relation to a few particular categories, showing that the most demanded activity was to seek for information about bus and train schedules, while searching information related to health was less common. During 2005 and 2006, females used the mobile search functionality more than men, but in 2007 differences were practically nonexistent. There were, however, significant differences between age cohorts: 36\% among people aged 15-19 expressed a demand for mobile search in 2007, compared to $18-21 \%$ among people aged $30-49$.

\subsection{Mobile search usage patterns}

As explained above, analyses on mobile search usage patterns are usually based on analyses of large-scale logs from search engine databases. Although other studies are cited, five main works are considered. In two subsequent articles, Kamvar and Baluja (2006, 2007) provided insights into Americans' mobile search 
behaviour based on a Google database, including more than 1 million page view requests. Baeza-Yates et al. (2007) analysed the characteristics of mobile search queries submitted to Yahoo in Japan, comparing 1 million mobile search queries with a set of 100,000 desktop search queries. While the aforementioned studies focused on mobile search behaviour with one specific search engine, Church et al. (2007) in their analysis (European countries, from late 2005) used a data set consisting of data from 30 search engines. The analysis was based on 600,000 European mobile subscribers, among which approximately 50,000 were mobile searchers, generating more than 30 million mobile Internet requests. In their subsequent study of European mobile subscribers, Church et al. (2008) carried out an exhaustive analysis of European mobile subscribers' use of mobile search engines. The data were based on 2.6 million subscribers, among which 260,000 had carried out at least one search request, generating a total of about 6 million mobile searches.

Despite the methodological difficulties comparing the above studies, we can draw some conclusions regarding mobile search usage activities and patterns. The discussion will be structured along the following three themes: (1) search input and scope; (2) search topics; (3) interaction with results.

\subsubsection{Search input and scope}

Church et al. (2008) discovered that queries contain circa 2.2 terms or 13.4 characters on average. These numbers are rather consistent with previous studies. Kamvar and Baluja (2007) report that the average mobile query was 2.56 words and 16.8 characters, and that it takes the average user about $40 \mathrm{~s}$ typing their query. Comparing that with their previous study (Kamvar and Baluja 2006), users type faster and they also click more often on links while exploring in their sessions. A similar study in Japan (Baeza-Yates et al. 2007) illustrates a close correspondence between the number of terms in mobile queries (2.29 terms per query, on average) compared to desktop queries ( 2.25 terms per query). The authors observe that the mean number of characters used for mobile queries is $7.9,{ }^{1}$ shorter than the 9.6 used for desktop queries, motivated in their opinion by the fact that it is more difficult to type with a mobile device.

Church et al. (2008) also analysed the number of searches per user and day. Based upon the $10 \%$ of users who actually used mobile search during the 1 week long test period, they concluded that the usage is rather limited, as more than half of the users only made one search query per day. On the other extreme there was a group of heavy users ( $16 \%$ of users) that submitted at least four unique queries per day.
Regarding how queries are performed, Church et al. (2007) realised that $23 \%$ of the queries were modifications of previous queries, i.e. most commonly simple substitutions of terms. In their subsequent study, Church et al. (2008) found that it had become more common for searchers to modify their searches, making it more appropriate to refer to these as 'search sessions'. An average such search session accounted for 8.6 queries, up from 5.8 queries in the previous study. Apparently users increasingly seem to have difficulties locating the information they were searching for. It may reflect the fact that - given the limited screen space to list the results - mobile Internet users make additional search requests to receive a similar number of results as the searcher of the desktop Internet.

In relation to this issue, a research team from Google have compared search usage patterns of computer, iPhone and other mobile users. They conclude that computer and iPhone users typically enter more words and characters into their queries than do users of other mobile devices. While computer and iPhone users are similar in this sense, their results do however also show that search is used for twice as many tasks with the computer than with iPhone and mobile devices (Kamvar et al. 2009).

\subsubsection{Search topics}

The research on mobile search activities involves two aspects: first, what type of search topics users are directed towards, and second, a taxonomy of mobile search behaviour intentions.

In Japan, the most popular mobile search queries are related to online shopping, sports and health (Baeza-Yates et al. 2007). In Europe and the USA, mobile search topics follow a different ranking: the most popular search category is adult content. ${ }^{2}$ Kamvar and Baluja $(2006,2007)$ find that besides adult material, the search topics of entertainment, Internet and telecom ${ }^{3}$ and local services are the most popular. Church et al. (2007) report that $53 \%$ of the top-500 queries were adult-related, while multimedia was the second most popular, accounting for about $10 \%$. In their subsequent study, Church et al. (2008) show that adult-related content accounts for about $60 \%$ of the top 500 mobile search queries. The rise in popularity of adult content is at the expense of searches for entertainment, multimedia and games. Kamvar and Baluja (2007) discuss two hypotheses about the high percentage of adult mobile search queries. Adult category used to be very prominent in early web history, until it declined in popularity. The first hypothesis is that mobile search will follow a similar decline the more it develops and attracts more users. This argument has also been suggested by 
Church et al. (2007). The second hypothesis is that people feel more comfortable querying adult terms on the mobile than on their computers. Mobile is perceived as a private device immune to strangers prying into digital history marks such as URL history lists and cached pages.

Regarding search topics, there has not been a clear conclusion in literature whether usage patterns are becoming more or less homogeneous. On one side, Kamvar and Baluja (2006) reported that the most popular query accounted for $1.2 \%$, while the top 1000 queries accounted for $22 \%$. In their subsequent study from 2007 they found that the top query accounted for $0.6 \%$ and the top 1000 queries for $17 \%$. Thus, mobile search query usage patterns would become less homogeneous. On the contrary, although their study is not fully comparable with Kamvar and Baluja (2006) since they analyse the top 500 queries instead of the top 1000 queries, Church et al. (2008) indicate that search queries are becoming more homogeneous. They find out that the most popular query accounts for $2 \%$ of all queries, and the top 500 queries account for a stunning $26 \%$ of all queries.

The second aspect of search topics regards the taxonomy of mobile search behaviour intentions. According to Church et al.'s (2008) taxonomy, mobile search queries can be categorised into three categories: navigational, informational and transactional. Navigational queries $(10.2 \%)$ refer to a class of queries where the immediate intent is to reach a particular site, such as domain suffixes or company names. ${ }^{4}$ Informational queries (29.4\%) involve situations in which users attempt to find information online but no further interaction is expected. ${ }^{5}$ The most used category by far is transactional queries $(60.4 \%)$, i.e. whenever the user seeks further interactions such as shopping, gaming, downloading files (images, videos, music, etc.). This category also includes adult-related queries (Church et al. 2008).

Church and Smyth (2007) carried out a complementary study of mobile search intentions and needs from a different perspective and with another methodology than the studies discussed so far. During 4 consecutive weeks in late 2007 , they followed a diary study approach with 20 participants having a mean age of 31 years. Their most important finding is that mobile searchers consider the context valuable for their information needs, especially with regard to location and time. When it comes to location, it is evident that people want to search for services/products that are geographically located close to where they live or work.

\subsubsection{Interaction with results}

The click-through behaviour, i.e. how users interact until they get to their desired objective, offers important insights for marketers and system optimisers. Its relevance becomes apparent when reading the results of the study by Church et al. (2006). For 7 search engines, the authors explored how search results are displayed sampling 20 different search queries. They conclude that a high proportion of the responses are either unsatisfactory or irrelevant.

There is only one study focusing on how users interact with the search results they gain, giving insight into the perceived relevance of search results and the extent to which search engines deliver good results to searchers. This study has been carried out by Church et al. (2008) and is based on a Google database (accounting for $85 \%$ of the search activities among users). Assuming that interactivity (number of clicks) with the displayed results is an indicator for relevance (the more clicks the higher the relevance) they recorded the number of clicks. Within one search session, only about 4 out of 10 searches led to the selection of one of the search results. Thus, it can be concluded that most result-lists failed to attract searchers' attention. An alternative explanation is that users were already satisfied by reading the result snippet. The authors question this argument since only 3 out of 10 searches were navigational. The results would then illustrate that the usefulness of mobile search engines is limited. One reason authors find is the limited level of usability: many mobile devices had weak interaction capabilities (especially at the time of the study). Having analysed that, assessing the real significance of these figures would have required to compare the results with those obtained repeating the search experience on a computer.

\section{Study rationale: context of attitudes towards and usage of mobile search}

The study rationale for this article involves the assessment of mobile search with regard to both attitudes and behaviour taking a contextual perspective. Our research proposition is defined through the following two questions:

- RQ1: What characterises the context of mobile search usage?

- RQ2: What characterises the context of attitudes towards mobile search?

As we embark on our empirical journey to explore the terrain of mobile search, we have to acknowledge previous research methodologies - and findings - on mobile adoption and use. Research approaches on 'mobile behaviour' vary significantly. Some studies have applied a User Cost Benefit Analysis (Chang and Pan 2009); others a more simple diffusion theory 
(Rogers 1995). Overall, the most popular approaches for research on mobile services and mobile Internet seem to be related to technology acceptance model (TAM) and the theory of reasoned action (TRA) (Pedersen 2005, Sell and Walden 2006, Al-Alak and Alnawas 2010, Chang et al. 2010).

Irrespective of the method, literature shows consensus on a number of important factors. Similar to other advanced information and communication technologies (ICTs), the adoption of mobile services is likely to follow some basic factors acting as drivers or barriers for acceptance and use.

Culture and lifestyle factors are relevant (Heres et al. 2002). Take, for instance, the case of Japan. The relatively early and extensive adoption of mobile Internet in Japan has been explained by their strong 'electronically oriented' culture and group conformity (Barnes and Huff 2003). Others have stressed the importance of the fact that Japanese tend to spend much time outdoors due to their small living space, which offers little privacy. A more recent investigation has shown that the Japanese hold more positive attitudes to using advanced mobile services than do Swedes (Westlund 2010b).

Leaving cross-cultural differences aside, the perceived user-friendliness and the perceived usefulness are the two key variables for mobile services acceptation (Chae and Kim 2004, Jung et al. 2009). Userfriendliness is closely related to the size of the screen and keypad. For a long time period, the perceived ease-of-use of mobile phones has been regarded as inferior in comparison to computers and other media. In this line, Verkasalo (2008) concluded from his quantitative analysis of a mobile service adoption process that user-unfriendly devices are the most outspoken argument for not using mobile services frequently, followed by the importance of pricing matters. Similar conclusions about user-friendliness and costs were drawn in a similar study (Kolmonen 2008). Those factors are changing, however. In line with West and Mace's (2010) analysis of the iPhone user experience, we conclude that the diffusion and use of smartphones have changed some previous assumptions. Indeed, there are a number of studies illustrating the relatively high-mobile Internet usage among smartphone users, compared to other mobile users. An example from Norway is a study from 2009 with 3917 Norwegians (Ling and Sundsøy 2009), where the results showed that iPhone users were accumulating 18 times the data traffic of other mobile users.

While the user-friendliness of touchscreen enabled smartphones indeed constitute an important explanation for mobile Internet usage, their related price plans are also an essential element in the equation. Earlier research has made evident that the variety and complexity of different pricing models have created perceived uncertainties. Those uncertainties have formed barriers for adoption and usage, and users have expressed preferences for appealing flat-rate tariffs (Westlund 2007b, Mitomo et al. 2009). In fact, a main - but not the first - reason for success, Apple was in a position to negotiate with mobile operators for flat-rate subscription offers for their launch of iPhone in the USA and Europe. This move forced other mobile telecom operators to follow suit.

Price counterbalances the second central dimension in studies of mobile adoption: usefulness. Previous research has laid forward that adoption has been slowed by an absence of fundamental needs for mobile Internet services (Westlund 2007b, Verkasalo 2008). What are the ways in which those needs will appear? Although the Bauer et al. (2005) conclusions date from 2005 they are most probably still valid: the main content drivers for mobile Internet use are entertainment and information. A new hope comes from mobile 2.0 applications for social networking, which are becoming increasingly popular. This was illustrated in international reports on the communications market already in 2008 (Ofcom 2008, ComScore M:Metrics 2008b). However, Pascu (2008b) warns against exaggerated optimism. After discussing the emergence of different types of social mobile applications - even integrating context-aware aspects that are unique to mobile devices - she notes that the diffusion of mobile devices does not automatically translate into a rapid adoption of mobile Internet services (Pascu 2008b). Anyway, the role of the mobile phone as an always-carried personal device able to maintain a constant link with the social network should be stressed (Feijóo et al. 2009b).

\section{Exploring usage and visions of mobile search}

The empirical investigation in this article is based on the results of a focus group study carried out in Gothenburg, Sweden, during 2009 in which we exercised standard methodological procedures. Our qualitative method was chosen since we approached a rather uncovered research terrain, which we aimed to explore in-depth through the life worlds of individual users, and within the context of their lives.

The respondents were recruited through several communication channels of the regional newspaper Göteborgs-Posten ${ }^{\circledR}$. Advertising banners were placed on the front page of the news website during five consecutive days (weekly reach; 350,000 unique visitors per week), as well as in the mobile specific website $(80,000$ unique page impressions per week). Personal encouragements to participate in the study were sent to subscribers of the newspaper's SMS-based news service (subscriber base of more than 500 people), to the 
subscribers of the company's newsletter (about 30,000 subscribers) and to the consumer panel (more than 1000 people). Furthermore, some respondents were recruited from a local high school.

The outcome of the recruitment process came down to five focus group sessions with a total of 29 respondents, aged from 17 to 54 years. There were 17 women and 12 men, being a mix of employed and students, non-users and heavy users. All respondents were provided with refreshments during the $1.5 \mathrm{~h}$ long focus group sessions, and were symbolically rewarded with two cinema tickets each. The five semi-structured focus group sessions were all recorded on videocamera. During the sessions, we used an interview manual with a set of themes that had been derived from our collaborative research review on the adoption and use of mobile search and Internet services summarised in the previous section. The interview manual was used to systematically explore the personal experiences and perceptions among the focus group members, which were interpreted using a qualitative content analysis approach.

Next, we present the results in an abstract and summarising form, to efficiently illustrate different patterns. At occasions we have inserted quotes to materialise a closer understanding of the interviewee subjects' personal life worlds.

\subsection{Characteristics of the mobile search usage context}

This section is devoted to investigating patterns of mobile Internet usage, putting the subsequent analysis of mobile search usage into a context. The mobile has become a ubiquitous and important component of the everyday lives of our respondents. We conclude that the respondents could be sorted into three main archetypes, based on how they make use of their mobile. We call these archetypes the traditionalists, the diversionists and the connected.

- The traditionalists are users who use the device only for interpersonal communication, via voice calls and SMS. They stress that they have not yet found it useful to make use of their mobiles in other ways, and several made clear that they have no intention to use their mobile for anything but these basic communicative functions.

- The diversionists make use of the mobile not only for interpersonal communication but also for multimedia functionalities such as the MP3player, calendar or camera. They do not use the mobile for connecting to the Internet, except when they occasionally send or receive photos via the MMS-function.
- The connected have adopted the mobile not only for interpersonal communication and multimedia diversion but also to connect to the Internet. The types of usage patterns within this archetype segment vary widely between different individuals, much depending on what kind of mobile device and price plan they have acquired.

Clearly, when referring to mobile search actual usage, only the connected could give us an insight into the nature of it. Amongst the connected, we make a further distinction into novice and advanced users. A novice user typically uses mobile Internet only while on the move, i.e. when she/he cannot access the Internet in any other way. Examples of such types of usage are when users access mobile Internet to gain information on timetables for public transport, sights or restaurants while on the go. The novice user possesses a mobile device that enables her or him to access mobile Internet, but she/he has not formed habits of doing so in everyday life. In turn, the advanced users have developed a completely different relationship to their mobile as an Internet tool. Rather than using it as a substitute to computer-based Internet and other media, they use it as a complementary source in everyday life. Advanced users access the Internet via mobile on the go, but also in situations where they have access to computers, such as at home, school or work, i.e. when they just consider it a more convenient alternative. For instance, some interviewees stressed that the mobile is the most accessible option to access the Internet during a commercial break on television or while lying in bed. Through their mobile devices, the advanced users have their always-on connection within the reach of an arm. These advanced users typically have acquired smartphones with touchscreen and a flat-rate price plan.

The difference in device and price plan between novice and advanced users helps to explain that advanced users have had developed more sophisticated terms of mobile Internet usage, involving mobile applications and transfers of large amounts of data. The traditional mobile device primarily offers four ways for Internet navigation; portals, inserting web address, bookmarks and search engines. With smartphones users can also access Internet through mobile applications. Our results showed that novice users typically accessed mobile Internet through the portal of their telecom operator. Portals are easily accessed and the headlines can be browsed free of charge making them 'attractive to get into the Internet'. Becoming advanced users did, however, stress that they find the content on portals too limited and the advertising often irrelevant and are starting to move on to explore websites and Internet content more 
independently. Using bookmarks is also commonplace among novice users. They must, of course, have found the website for the bookmark in the first place, either through the portals content, search engines or by inserting the entire web address manually. Search engines are used only occasionally. As a final remark, the novice users expressed large demand for more mobile specific services, which had to do with the limited user-friendliness of their mobile devices. Sofia $(F, 26)$ expresses appreciation for websites that have been specifically adjusted to the mobile, such as the mobile website of the public transport company in the Gothenburg region. She describes it as a simple and clean text-based website containing two fields; 'from' and 'to'. The user can easily insert their query and search for upcoming departures for the public transport system.

The advanced users, on the contrary, seldom use portals, but rather bookmarks, search engines and mobile applications. Some users preferred and also predominantly used content specifically adapted to the logic of the mobile, in the form of mobile sites or applications. Others also made use of traditional Internet sites, from their point of view, they become most satisfied when they can access the full version of the Internet sites; with their mobiles, as they do with their computer(s). Lina $(F, 23)$ and Stefan $(M, 23)$ for example, have tried a number of mobile search engines but are most satisfied when they use mobile search from traditional search websites. Advanced users access similar types of content as with their computer(s), such as news and social networking sites as well as collecting information about public transport, recipes, weather, time and places.

The distinction between novice and advanced users is also reflected in other usage features. Regarding search input and scope, interviewees had difficulties describing the exact number of words and characters of their mobile search queries. The advanced users - as far as they can estimate - usually type a few keywords when they make their searches. Sometimes they do not access the information they searched for, and therefore modify their search input. Many of them declare, however, that a high proportion of search results are unsatisfactory. This is a really important point as early unsatisfactory experiences of using mobile search can make people refrain from performing such activities again. For example, Lisa $(F, 26)$ once used mobile search to know the final score of a football match while at a summer party in a cottage. Since it took her the 'eternity' of $15 \mathrm{~min}$ to retrieve the information, she has felt discouraged to try mobile search again. Others, however, have continued to use mobile search after a bad experience, and most likely also have developed their skills in managing it well.
Another area addressed in our focus group was search topics. As discussed in Section 2.2.2. Church et al. (2008) propose a taxonomy of three types of searches called navigational, informational and transactional. As we explored the mobile search behaviours of our respondents, a fourth type of search emerged, which we will from here on refer to as leisure search. The data gathered from the focus groups indicate that every mobile search user occasionally carries out navigational or logistical searches. In general, such searches are more often carried out while on the go, in situations when people do not have access to desktop Internet. Magnus $(\mathbf{M}, 43)$ values the freedom to access mobile Internet information whenever needed. However, as a novice user, he uses mobile search only if he absolutely must; otherwise he waits until he can make the search from a computer. Advanced users make, in general, more sophisticated navigational or informational searches. They desire geographical positioning through map services, such as finding directions or the address of a restaurant where they have an appointment. Transactional searches are rather uncommon. Those who did carry out such searches were, mainly, advanced users. It was also these advanced users who carry out what we refer to as leisure searches. Here, search is in the realm of spending or organising private time, even to the extreme to enjoy the search process by itself. Beyond searching at the specific occasions where they perceive it as necessary, users use it for fun or spend spare time, both on the go and at home. Typically users search for content such as lyrics, videos, music and images.

If the question is framed in the future tense, respondents primarily venture a great future usefulness in logistical information searches. People envision easily interacting with each other on the go and adjusting their arrangements in real time, making more loose arrangements with each other. This freedom increases by the possibility of searching for shows, films or restaurants after meeting. In a similar way, the habit of planning beforehand prior to doing routine activities could also be altered, but not dramatically. For example, people used to consult timetables for public transport at their computer before their departure at home or at the office. Some people stress that it works perfectly well to continue to do so, and will only use the mobile when there are no other means to gain the information. On the other hand, others argue that the mobile is a very convenient way to access information on the go, strongly advocating such usage.

A final comment on the control of the information flow: most users, particularly the novices, prefer to use mobile Internet on demand when they really feel that they need it. When it comes to push-services, some 
users tend to 'lose the feeling of control'. Others, on the contrary, have simply assumed the behaviour changes associated with constant accessibility. Lina (F,23), for instance, says she has intensified significantly her usage during the 6 months she had been using her iPhone. She acknowledges that it is not socially correct to browse the Internet while being with others, but she cannot stop checking emails and updates on Facebook, and she tries to do so discreetly. While socialising with peers she hides her iPhone in a book or purse while using it for mobile Internet. She argues that she finds it comforting to take a pause from her social environment and just focus on herself and her needs by using mobile Internet. This is a way for her to create some personal space within the public domain.

\subsection{Attitude characteristics of the mobile search context}

In this final section, we navigate through the respondents' personal attitudes towards current and future use of mobile Internet and search. We explored empirically why novices use mobile Internet on seldom occasions, how advanced users make sense of their user experiences and the conditions under which non-users would become regular users. As a summary, respondents perceive as most important drivers of (or barriers to) further mobile Internet service development and adoption: usefulness, user-friendliness, costs, "expressive functionality', but also perceptions of private integrity.

The first line of argument focuses usefulness, in the sense that many respondents have not yet experienced a need to access information with their mobile, since they usually have good access to Internet via their computer(s). They have no problem in waiting to access information until they can use a computer, and may even feel stressed about using the mobile for multimedia content. Advanced users on the other hand stress that the usefulness is constantly improving, thanks to the growing amount of content and services one can access with the mobile. They also point up that the appeal of the mobile device to be used as an Internet tool is high: it is always carried and it gives users the freedom of accessing information from a range of sources on their own conditions.

Another line of argument centres on costs. Many respondents are uncertain how much accessing Internet via mobiles will cost them. People are largely unaware and many find it difficult to know the real costs charged to access the Internet. Some believed they are charged per minute; others thought by traffic. Both groups, however, were not aware how their usage would translate into costs. Those who checked their bills come to the conclusion that using mobile Internet for services that are predominantly text-based is not expensive, and will continue doing so. Others did not check their bills in detail and had refrained from usage believing it to be expensive. Concerning the overall costs, many are not willing to pay for mobile Internet access at all, since they are already paying for Internet access via their computers. Others would pay for access to the Internet with the mobile but think that the present prices are too high. On the contrary, advanced users stress in a positive sense that costs can be controlled with flat-rate subscriptions. Several of the respondents had recently transferred from pay-as-yougo data plans to subscriptions with a fixed flat-rate per month, which had reduced not only the costs for usage but also the anxieties for the costs. Once using flat-rate, they feel comfortable in exploring the width of mobile Internet with their mobile device, including services such as mobile TV that cause heavy loads of data transfer.

Regarding user-friendliness, some novice and seldom users stressed that the user experience of accessing information with the mobile they use is not up to the mark, in particular when compared to their experience of accessing information on the Internet via their computer(s). Particularly, most of those who use mobile devices with a keypad stressed that it is troublesome to navigate mobile Internet. Some also stressed that browsing Internet sites is considered too slow, which is partly caused by the insufficient bandwidth of mobile broadband, and partly by the limited processing power of mobile devices. The respondents agree that there must be a sound balancing between the size of the device and its usability. A larger display is preferred for the mobile Internet experience, but not at the expense of being cumbersome to be carried along. Again, the opinion of advanced users is different. For them, mobile devices have become very user-friendly, which has to do with larger screens, the touchscreen interface, and improved navigation, applications and services.

Some examples illustrate actual limitations. Johan $(M, 33)$ finds it difficult to navigate and find information on the mobile as his mobile only shows the top five results. He normally does not click to see the next page of results as it takes too much time. Sara $(F, 18)$ considers search process to involve too many steps, and thus cumbersome. Lennart $(\mathrm{M}, 34)$ complains having to make too many modifications of the search queries, taking him unreasonably long time particularly when using his 'relative old' mobile. Stefan $(\mathbf{M}, 23)$ shows little patience when conducting searches with the mobile. He gets stressed when the requested information is difficult to find. Fredrik $(M, 18)$ finds it troublesome to enter Google search queries with his 
mobile, mostly because the search field is too small. He considers the interface not being well adapted from the computer to the mobile, and would prefer getting rid of excessive information to enable an improved overview.

The mobile is more than a consumption good: the design reflects the 'image of his/her owner' turning it into an expressive marker of identity and status. From earlier studies in Sweden we know that only few years ago people wanted small device. A mobile device with a large screen was identified with the business community. This raised a conflict between instrumental and expressive needs, and at that time expressive needs were valued the highest (Westlund 2007a). By the time of our study the situation had changed. The iPhone and other smartphones with large touchscreens have become very appealing, and several express a desire to acquire such devices as they satisfy both their instrumental and expressive needs. Yet a number of the novice users stress that the design of the mobile can be just as important as its functionality. These users, who do not value mobile Internet functionality as useful, argue that small mobiles are more practical and appealing. For example, Sofia $(F, 26)$ wants people to perceive her in a specific way through her mobile, and it is important to her to have a mobile with appealing design and outlook. In this line, she finds that although the iPhone is appealing in terms of functionality and design, the hype that has surrounded its introduction has made it too commonplace for her to identify with. This view was shared also by other participants.

Surprisingly, security, privacy and trust matters did not come too much to the fore during the focus group's initial discussion. The respondents seem overall happy using the mobile for Internet services and content in the current situation, possibly because their experience of personalised services is yet limited. People are largely unaware that mobile content providers might monitor usage to optimise a personalised proposition of services, for example for location-based services. It is generally difficult for people to visualise how specific location-based services would fit their everyday life needs. We may then return to the discussion on usefulness. Anna $(F, 27)$ argues that any personalised services must be tailored to the user's needs: info of traffic jams is only relevant when she drives a car and is on her way. All in all, a number of respondents said they would be willing to register personal information if this enhances the information they can access. On the other hand, although they were not fully aware of those problems before the discussion started, some of the participants expressed concern over companies' use of their personal data and expressed desire to be able to control this type of information. Some say they get personally offended if the information is too personal, as it affects their personal integrity.

\section{Concluding remarks}

With this article we have summarised the current research frontier on the emerging field of mobile search, as well as exploring new terrains in this growing field of study. Our qualitative study has explored two particular research questions; within the first we have identified the three archetypes of the traditionalists, the diversionists and the connected. We have furthermore specifically seen that among the connected there are both novice and advanced users.

The novice user turns to mobile Internet occasionally, mostly on the go, using a traditional mobile device. They value the usability and user-friendliness levels as low, and perceive costs as uncertain or high. They use basically mobile portals but also bookmarks and some mobile search as they explore the mobile Internet. The advanced users have integrated their use of mobile Internet into everyday life, using it both on the go and in the domestic context. Their navigation through the mobile Internet is more free and individualised, using bookmarks, applications and search to access the content they desire. Our exploration into the patterns of usage among the advanced user group illustrates a move away from locked- in and portal-based mobile Internet navigation, and towards more independent usage where both mobile applications and mobile search are becoming increasingly important. Contrary to early ideas on how to develop Internet for the mobile as a limited version, the advanced users want to access the entire Internet with their mobile devices, but with added mobile functionality. We interpret that such mobile logic involves the use of personalised and context-based services, probably through the value proposition of iPhone- or Android-based applications (or equivalent). It is also among these advanced users we uncovered a new dimension of search topics, namely leisure search. Leisure search has an orientation towards entertainment and discovery. Such activities are taking place to spend private time, enjoying the process of searching and locating content, services and applications.

Regarding the second research question on the context of attitudes to mobile search, we have confirmed the importance of factors such as usefulness, userfriendliness and costs. Additionally, we have noted the transformative importance of expressive functionality and the issue of private integrity. It also becomes evident that as people evaluate their experiences of mobile search, they make comparisons based on their experiences with computer-based search.

Future developments of mobile search must be sensitive to the mobile logic. Some ideas have been yet 
advanced. Karlson et al. (2006) argue that text entry and search off the device should be adapted to mobiles. Arter et al. (2007) explored opportunities for in-situ sharing of user's mobile search activities, presenting to a user in a given geographical location the search queries of other people at the same place. Similarly, Church and Smyth (2008) proposed a context-sensitive mobile search that combines location, time and community preferences using previous results and queries from an interactive map-based interface. In a more recent study, Church and Smyth (2009) concluded that mobile search should be integrated with social networks and the contexts of time and place. The use of tagging, clouds and usergenerated content in mobile search has been underlined as well by Kim et al. (2010) or Nordström et al. (2009). In fact, these advances are not just confined to the academic realm. Application stores currently witness a 'new wave' of search that combines conventional search with location information, content from social networks and the possibility of multimedia inputs (voice and/or pictures taken by the camera in the device). These solutions partly merge with the domain of recommendation engines, making it more convenient to call them 'mobile search applications'.

Ultimately, the mobile device as multimedia has become a disruptive media, transforming the everyday lives of our global population. Technology enables much change, but it is the social force of users that currently is changing the role of mobile Internet in our society. Mobile search should be understood and promoted based on its compatibility with the modern lifestyle on the go, rather than through its technological capacity. Therefore, the logic of mobile search must be developed to match the increasingly mobile, global, connected and individualised users.

\section{Acknowledgements}

This work has been partially supported by the European Commission's ICT programme through the Contract CHORUS + (Coordinated approacH to the EurOpean effoRt on aUdio-visual Search engines Contract 249008). We also want to show our appreciation to Göteborgs-Posten for their collaboration with facilitating the focus group study. Oscar Westlund wants to acknowledge the support given him from Tidningsfonden för Fortbildning in Sweden. In addition, Claudio Feijóo acknowledges the support from the research project on the evolution of mobile media in Spain (CSO2009-07108) where he participates.

\section{Notes}

1. This figure is much less for Japan than that quoted for Europe and USA (almost the same). This difference may possibly indicate only that in mobile phones you use Latin characters of kajin or hiragana. Therefore, the number of characters per query is not an adequate indicator. The terms per query (i.e. how many words) is a more useful one. Consequently there is hardly any difference between countries. This makes sense and is perfectly in line with desktop web search findings.

2. Often, and especially in the USA, the term adult content covers more than only pornography; it includes also dating services and other social relationships (not necessarily sex-related).

3. The 'Internet and telecom' category refers to searches such as looking up Facebook ${ }^{(}$, MSN $\left.^{(}\right)$, etc.

4. The user may be aware of the name of company or website name beforehand, but he/she is perhaps not aware of the website address, especially not the mobile website address.

5. For example, a group of friends meet at a restaurant and initiate a discussion on politics, and realise that they cannot agree on the name of a minister.

\section{References}

Al-Alak, A.M.B. and Alnawas, A.M.I., 2010. Mobile marketing: examining the impact of trust, privacy concern and consumer's attitudes on intention to purchase. International Journal of Business and Management, 5 (3), 28-39.

Arter, D., et al., 2007. Incidental information and mobile search. Proceedings of the 9 th international conference on human computer interaction with mobile devices and services (Mobile HCI 07)), 9-12 September, Singapore, 413-420. Available from: www.cs.swan.ac.uk/ csmatt/ qna/QnA\%20Resources/47CE6897-3DFD-4FF4-AD9193CDA0D23C8D_files/QnAMobileHCI.pdf

Baeza-Yates, R., Dupret, G., and Velasco, J., 2007. A study of mobile search queries in Japan. Proceedings of the 17 th international conference on World Wide Web ( $W W W$ 2007)), 8-12 May, Beijing, 257-266. Available from: www2007.org/workshops/paper_50.pdf

Barnes, J.S. and Huff, L.S., 2003. Rising sun: iMode and the wireless Internet. Communications of the $A C M, 46$ (11), 78-84.

Bauer, H.H., et al., 2005. Driving consumer acceptance of mobile marketing: a theoretical framework and empirical study. Journal of Electronic Commerce Research, 6 (3), 181-192.

BIA/Kelsey, 2009. Mobile consumer study reveals surge in non-voice communications, driven by smartphone proliferation. Press release, 17 November. Available from: http:/ www.fiercewireless.com/press-releases/bia-kelseymobile-consumer-study-reveals-surge-non-voice-communications-driven-smar-0

Bohlin, E., Olsson, T., and Westlund, O., 2007. Mobile barometer 2007 - an analysis of the Swedish mobile society. Tokyo: Mobile Society Research Institute Report, NttDoCoMo. Available from: http://www. moba-ken.jp/wp-content/pdf/research07-01.pdf

Bouwman, H., et al., 2009. Reconsidering the actual and future use of mobile services. Information Systems and eBusiness Management, 7, 301-317.

Chae, M. and Kim, J., 2004. Do size and structure matter to mobile users? An empirical study of the effects of screen size, information structure, and task complexity on user activities with standard web phones. Behaviour \& Information Technology, 23 (3), 165-181.

Chang, S.E., Chen, S.Y., and Liu, Y.H., 2010. A user study of accessing web applications via voice cellular phone: a model comparison approach. Behaviour \& Information Technology, 28 (5), 471-484.

Chang, S.E. and Pan, Y.-H.V., 2009. Exploring factors influencing mobile user's intention to adopt multimedia messaging services. Behaviour \& Information Technology. iFirst, DOI: 10.1080/01449290903377095. 
Church, K., et al., 2008. A large scale study of European mobile search behaviour. Proceedings of the 10 th international conference on human computer interaction with mobile devices and services), 2-5 September, Amsterdam. New York: ACM Press, 13-22.

Church, K., et al., 2007. Mobile information access: a study of emerging search behaviour on the mobile Internet. $A C M$ Transactions on the Web, 1 (1), Article 4.

Church, K., Smyth, B., and Keane, M.T., 2006. Evaluating interfaces for intelligent mobile search. Proceedings of the 2006 international cross-disciplinary workshop on Web accessibility (W4A), 23-26 May, Edinburgh. New York: ACM Press, 69-78.

Church, K. and Smyth, B., 2007. Understanding mobile information needs. Proceedings of the 10th international conference on human computer interaction with mobile devices and services, 2-5 September, Amsterdam. New York: ACM Press, 493-494.

Church, K. and Smyth, B., 2008. Who, what, where and when: a new approach to mobile search. Proceedings of the $13 \mathrm{th}$ international conference on intelligent user interfaces (IUI'08), 13-16 January, Maspalomas. New York: ACM Press, 309-312.

Church, K. and Smyth, B., 2009. Understanding the intent behind mobile information needs. Proceedings of the 2009 International Conference on Intelligent User Interfaces (IUI'09), 8-11 February, Sanibel Island. New York: ACM Press, 247-256.

Compete, 2010. Smartphone owners: a ready and willing audience. Press release, 12 March. Available from: http:/blog. compete. com $/ 2010 / 03 / 12 /$ smartphone-owners-a-ready-andwilling-audience/

ComScore M:Metrics, 2008b. Mobile social networking driving growth of the mobile Internet in Europe. Press Release, 29 January. Available from: http://www.comscore.com/ Press_Events/Press_Releases/2009/1/Mobile_Social_Net working_Europe

ComScore $\bar{M}$ :Metrics, 2008a. Mobile search grew 68 percent in the U.S. and 38 percent in Western Europe during past year. Press Release, 15 September. Available from http:// www.comscore.com/Press_Events/Press_Releases/2008/ 09/US and Western Europe Mobile Search Increases

Cui, Y. and Roto, V., 2008 . How people use the web on mobile devices. Proceeding of the 17 th international conference on World Wide Web, 21-25 April, Beijing. New York: ACM Press, 905-914.

Feijóo, C. and Gómez-Barroso, J.L., 2009. Factores clave en el acceso móvil a contenidos. El Profesional de la Información, 18 (2), 145-154.

Feijóo, C., et al., 2009a. Exploring a heterogeneous and fragmented digital ecosystem: mobile content. Telematics \& Informatics, 26 (3), 282-292.

Feijóo, C., et al., 2009b. The next paradigm shift in the mobile ecosystem: mobile social computing and the increasing relevance of users. Communications \& Strategies, 75, 57-78.

Feijóo, C., Gómez-Barroso, J.L., and Martínez, I.J., 2010. Nuevas vías para la comunicación empresarial: publicidad en el móvil. El Profesional de la Información, 19 (2), $140-148$.

FierceWireless, 2010. Google: One in three mobile searches has local intent [online]. Available from: http://www. fiercewireless.com/ctialive/story/google-one-three-mobilesearches-has-local-intent $/ 2010-03-22$ ? utm_medium $=$ nl\&ut m_source $=$ internal [Accessed 22 March 2010].
Goggin, G., 2009. Adapting the mobile phone: the iPhone and its consumption. Continuum, 23 (2), 231-244.

Gohring, N., 2010. Google betting big on mobile [online] Available from: http://www.pcworld.com/article/191560/ google_betting_big_on_mobile_executive_says.html [Accessed 15 March 2010$]$.

Haddon, L. and Vincent, J., 2008. Children's broadening use of mobile phones. In: G. Goggin and L. Hjorth, eds. Mobile technologies: from telecommunications to media. Abingdon: Routledge, 37-49.

Heres, J., Mante, E., and Pires, D., 2002. Factors influencing the adoption of broadband mobile Internet [online]. Report from the Capabilities Working Group of COST Action 269. Available from: http://www.cost269.org/working\% 20group/DocCapabilities/Ch_8.doc [Accessed 9 October 2010]

Horrigan, J., 2009. Wireless Internet use [online]. Washington: Pew Internet. Available from: http:/pewInternet. org/ /media//Files/Reports/2009/Wireless-Internet-Use. pdf [Accessed 9 October 2010]

Jung, Y., Pérez-Mira, B., and Wiley-Patton, S., 2009. Consumer adoption of mobile TV: examining psychological flow and media content. Computers in Human Behaviour, 25 (1), 123-129.

Kamvar, M., et al., 2009. Computers and iPhones and mobile phones, oh $m y$ ! Paper presented at the WWW 2009 Madrid! Conference, at the track: user interfaces and mobile web/session: mobile web, 20-24 April, Madrid. Available at: http://static.googleusercontent.com/ external_content/untrusted_dlcp/research.google.com/ es//pubs/archive/35252.pdf [Accessed 9 October 2010].

Kamvar, M. and Baluja, S., 2007. Deciphering trends in mobile search. Computer, 40 (8), 58-62.

Kamvar, M. and Baluja, S., 2006. A large scale study of wireless search behavior: Google mobile search. Proceedings of the SIGCHI conference on human factors in computing systems, 22-27 April, Montreal, 701-709. Available from: http:/www.esprockets.com/ papers/kam var-baluja.chi06.pdf

Karlson, A.K., et al., 2006. FaThumb: a facet-based interface for mobile search. Proceedings of the SIGCHI conference on human factors in computing systems, 22-27 April, Montreal. New York: ACM Press, 711-720.

Kim, S., et al., 2010. Mobile web 2.0 with multidisplay buttons. Communications of the $A C M, 53$ (1), 136-141.

Kolmonen, L., 2008. Mobile search engine survey. Paper presented at the Research Seminar on Telecommunications Business, 14 April, Helsinki University of Technology. Available from: http://www.tml.tkk.fi/Opinnot/T109. 7510/2008/Eng1.pdf [Accessed 9 October 2010].

Ling, R. and Sundsøy, P.R., 2009. The iPhone and mobile access to the Internet. Paper presented at the ICA preconference on mobile communication, 20 May, Chicago. Available from: http:/lirneasia.net/wp-content/uploads/ 2009/05/final-paper_ling_et_al.pdf [Accessed 9 October 2010].

Mitomo, H., Otsuka, T., and Nakaba, K., 2009. A behavioral economic interpretation of the preference for flat rates: the case of post-paid mobile phone services. In: P. Curwen, J. Haucap, and B. Preissl, eds. Telecommunication markets: drivers and impediments. Heidelberg: Physica-Verlag, 59-73.

NTT DoCoMo, 2007. Comparison of general outlook for mobile societies in China and Japan (Global questionnaire). Tokyo: Mobile Society Research Institute. 
Nordström, E., et al., 2009. Search-based picture sharing with mobile phones. Proceedings of the tenth ACM international symposium on Mobile ad hoc networking and computing, 18-21 May, New Orleans. New York: ACM Press, 327-328.

Ofcom, 2008. The international communications market 2008 [online]. London: Ofcom. Available from: http://www. ofcom.org.uk/research/cm/icmr08/icmr08.pdf [Accessed 9 October 2010].

Opera, 2010. State of the mobile web January 2010 [online]. Available from: http://www.opera.com/smw/ [Accessed 9 October 2010].

Pascu, C., 2008a. An empirical analysis of the creation, use and adoption of social computing applications [online]. Institute for Prospective Technological Studies, JRC Scientific and Technical report, EUR 23415 EN. Available from: http://ipts.jrc.ec.europa.eu/publications/pub. cfm?id=1684 [Accessed 9 October 2010].

Pascu, C., 2008b. Towards convergence of social computing with mobile - a thought piece on mobile trends and futures. Paper presented at the 19th European Regional ITS Conference, 18-20 September, Rome.

Park, T., Shenoy, R., and Salvendy, G., 2008. Effective advertising on mobile phones: a literature review and presentation of results from 53 case studies. Behaviour \& Information Technology, 27 (5), 355-373.

Pedersen, P.E., 2005. Adoption of mobile Internet services: an exploratory study of mobile commerce early adopters. Journal of Organizational Computing and ElectronicCommerce, 15 (3), 203-222.

Ramos, S., Feijóo, C., and Gómez-Barroso, J.L., 2009. Next generation mobile network deployment strategies. Journal of the Institute of Telecommunications Professionals, 3 (1), 13-19.

Reding, V., 2008. Digital Europe: the Internet mega-trends that will shape tomorrow's Europe. Speech at the European Internet Foundation Special Event A view of the Digital World in 2025, 13 November, Brussels. Available from: http:/europa.eu/rapid/pressReleasesAct ion.do? reference $=\mathrm{SPEECH} / 08 / 616 \&$ format $=\mathrm{PDF} \&$ aged $=$ $0 \&$ language $=\mathrm{EN} \&$ guiLanguage $=$ en $[$ Accessed 9 October 2010].
Rogers, E., 1995. Diffusion of innovations. New York: The Free Press.

Sell, A. and Walden, P., 2006. Mobile digital calendars: an interview study. Proceedings of the 39th Annual Hawaii International Conference on System Sciences, HICSS'06). 4-7 January, Kauai, New York: IEEE Computer Society, Vol 1, 23b.

Verkasalo, H., 2008. From intentions to active usage: a study on mobile services in Finland. Paper presented at the 19th European regional ITS conference, 18-20 September, Rome.

West, J. and Mace, M., 2010. Browsing as the killer app: explaining the rapid success of Apple's iPhone. Telecommunications Policy, 34 (5-6), 270-286.

Westlund, O., 2007a. Mobiltelefonanvändning - en forskningsöversikt (How people use mobile devices - a research overview). JMG Report series number 47. University of Gothenburg.

Westlund, O., 2007b. The adoption of mobile media by young adults in Sweden. In: G. Goggin and L. Hjorth, eds. Proceedings of Mobile Media 2007, 2-4 July, Sydney, University of Sydney. Chapter 12.

Westlund, O., 2008. From mobile phone to mobile device: news consumption on the go. Canadian Journal of Communication, 33 (3), 443-463.

Westlund, O., 2010a. De mobilt uppkopplade svenskarna ("Mobile connected Swedes"). In: L. Weibull and S. Holmberg, eds. Nordiskt ljus (Nordic lights). Livrena: University of Gothenburg, 453-465.

Westlund, O., 2010b. New(s) functions for the mobile: a cross-cultural study. New Media Society, 12, 91-108.

Wilken, R. and Sinclair, J., 2009. Waiting for the kiss of life: mobile media and advertising. Convergence, 15 (4), 427445.

Wilson, J., 2006. 3G to Web 2.0? - can mobile telephony become an architecture of participation? Convergence, 12 (2), 229-242. 